\title{
Jovem, Mostre a Sua Cara: Um Estudo das Possibilidades e Limites da Escolha Profissional
}

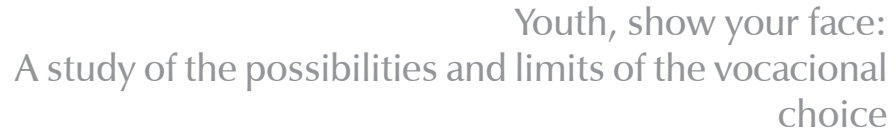

Maria Sara de Lima Dias \& Dulce Helena Penna Soares

Universidade Federal de Santa Catarina
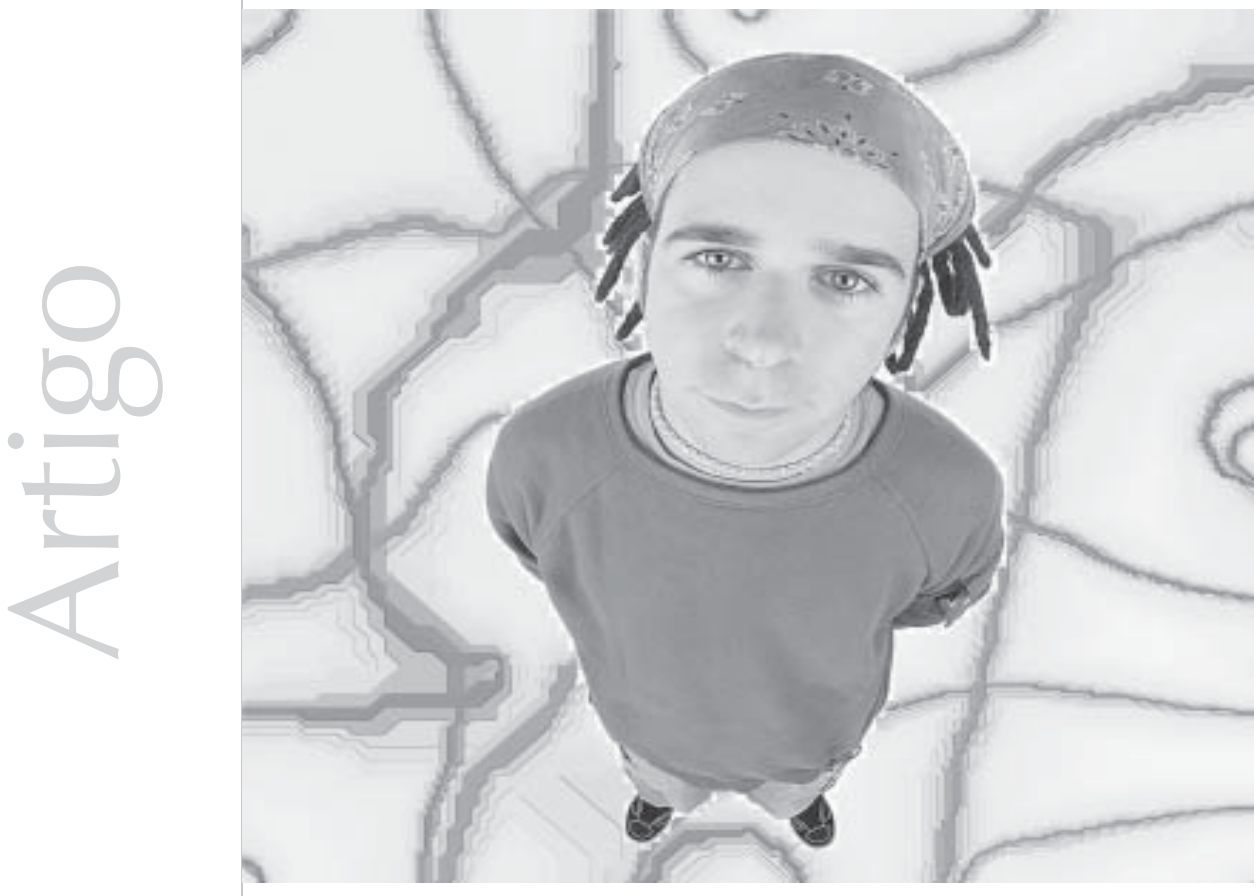


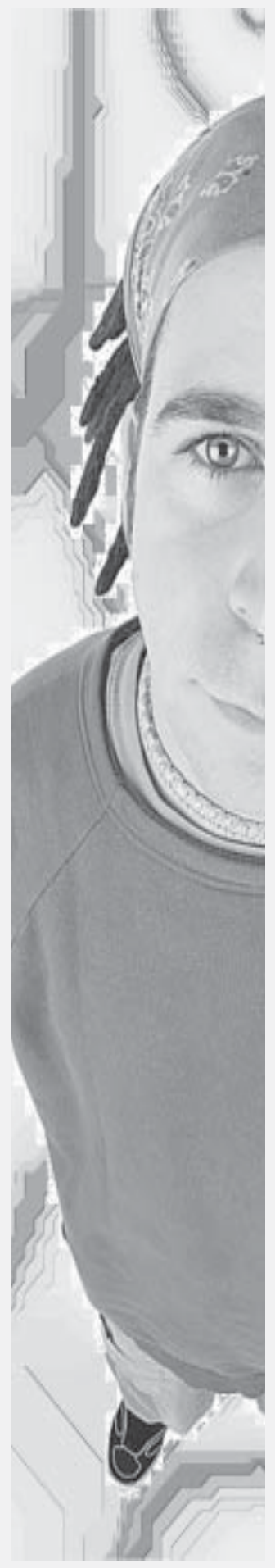

Resumo:Este trabalho apresenta o relato de um estudo com o objetivo de analisar as condições psicossociais envolvida nas escolhas dos jovens em seus projetos profissionais, a partir da vivência de uma das autoras no Projeto Jovem, mostre a sua cara!, desenvolvido na Ilha do Mel, Paraná. A Psicologia sociohistórica e a metodologia qualitativa embasaram o estudo realizado, em que foram utilizadas técnicas de orientação profissional. A análise das narrativas produzidas pelos grupos ressaltou aspectos sobre a realidade do trabalho e sobre os limites e as possibilidades de escolhas profissionais, que refletem a situação particular desses jovens. A relevância deste relato centra-se no fato de que qualquer projeto de intervenção requer o conhecimento dos aspectos socioculturais e das dinâmicas próprias de uma comunidade específica como essa. A prática da orientação profissional pretendeu ter contribuído para mobilizar a participação dos jovens no projeto nas suas múltiplas dimensões e ter fornecido subsídios para as instituições envolvidas, tanto neste quanto em outros projetos dessa natureza.

Palavras-chave: orientação profissional, escolha, trajetória de vida, identidade cultural.

Abstract: This work presents research which has the objective to analyze the psicossocial conditions involved in the choices of the young in their professional projects, based on the experience of one of the authors in the project Young, show your face!, developed in the Ilha do Mel island, Paraná. Social-historical Psychology and qualitative methodology were the base of the research, that included also the techniques of vocacional guidance. The analysis of the narratives produced from the groups highlighted aspects on the reality of the work and on the limits and possibilities of professional choices, what reflected the particular situation of these young people. The relevance of this story is centered in the fact that any project of intervention requires the knowledge of the socialcultural aspects and the proper dynamic of the community. The practice of the vocacional guidance may have contributed to mobilize the participation of the young in the project in its multiple dimensions, supplying subsidies for the involved institutions, in this as well as in other projects of this nature.

Key words: vocational guidance, choice, life choices, cultural identity. 
Em particular, no caso dos jovens da Ilha do Mel, as atribuições identitárias são tecidas sobre quem são os jovens nativos ou os não-nativos.
Este trabalho consiste no relato de um estudo a partir da experiência de uma das autoras, convidada para participar como psicóloga do projeto Jovem, mostre a sua cara!, financiado pelo MMA/FNMA, convênio no 092/2004, e executado pelo Mater Natura - Instituto de Estudos Ambientais, projeto esse que objetivou desenvolver o senso crítico e participativo dos jovens moradores da llha do Mel (Paranaguá PR), para a identificação e resolução dos problemas socioambientais aos quais estão submetidos, através de um processo interativo. Para tal, foram realizadas reuniões de planejamento das atividades e procedimentos a serem adotados, tendo em vista as possibilidades e limites do trabalho de campo. As atividades foram estruturadas, a partir das discussões e reflexões da equipe técnica, sobre a dependência de recursos da comunidade, e tomaram, como pano de fundo, a instabilidade e a perspectiva do número possível de jovens que participariam efetivamente dos grupos de trabalho.

Algumas pesquisas relatadas a seguir, sobre a temática dos jovens e a situação de residentes em ilhas, auxiliam a pensar o contexto e a problematizar o estudo. Santos (2003) analisa o uso da memória pelas ciências sociais a partir da investigação de fontes orais e escritas, levando em conta cinco narrativas sobre o assassinato de um lavrador da llha Grande. O autor procura mostrar como as memórias se relacionam a perspectivas e códigos existentes entre grupos de pertencimento e como elas podem fornecer dados importantes sobre contextos, processos e conflitos sociais que fazem parte da vida dos narradores residentes na ilha.

Sobre o ecoturismo na llha Grande, Prado (2003) analisa as implicações da introdução do turismo na ilha, abruptamente transformada num local de grande procura por parte de turistas e veranistas. Indica as conseqüências dessa mudança em contextos nos quais ele antes não existia e a questão da polaridade entre "nativos" e "não-nativos", aflorada ali em razão da intensificação do turismo e que corresponderia a uma barreira na aceitação de uma ideologia ambientalista.
Examina-se um paradoxo contemporâneo: à medida que os atuais processos de globalização se intensificam, a manifestação de identidades culturais diferenciadas, em vez de se esbater, parecem tender a se multiplicar. Para Costa (2002), o tema permanece polêmico, nas ciências sociais, quanto aos fatos observáveis e quanto à interpretação do seu significado, e o autor procura contribuir para essa análise recorrendo a alguns exemplos de investigação sobre processos identitários no meio urbano atual ou relacionados a este.

Em particular, no caso dos jovens da Illha do Mel, as atribuições identitárias são tecidas sobre quem são os jovens nativos ou os não-nativos. Os processos identitários se acentuam entre aqueles a quem pertence o território por direito de nascimento e aqueles que vieram de fora, ao mesmo tempo em que os não-nativos, depois de determinado tempo de permanência na ilha, também passam a ser aceitos como parte da mesma comunidade, ou, apesar do tempo, continuam não sendo aceitos em função da posição social que ocupam. Essas considerações foram verificadas no trabalho de campo, quando da visita dos técnicos para a elaboração do projeto. A história de cada sujeito, determinada pelo local de nascimento, pode, no contexto da Illha do Mel, promover processos de identificação maior ou menor entre os membros do grupo e acirrar as diferenças ou semelhanças entre os sujeitos. Os processos de identificação desses grupos podem reduzir ou ampliar a efetiva participação em projetos de participação ou nas suas atuações comunitárias. Assim, a busca por elementos comuns aos jovens, como dificuldades de escolaridade, necessidades de espaços de lazer, objetivos em relação à Ilha do Mel e a necessidade de preservação da ilha, são elementos comuns que podem efetivamente servir como canalizadores para acelerar a participação e a integração dos jovens nos grupos comunitários.

Decorrente dessas constatações, surge a necessidade da intervenção do psicólogo, cujo objetivo foi possibilitar um papel ativo aos jovens através de técnicas e vivências grupais e promover maior participação e integração dos 
mesmos nas atividades propostas pelo projeto, de modo a promover uma integração entre os jovens que superasse efetivamente a polaridade entre nativos e não nativos, entre os da ilha e os de fora, com respeito ao contexto e aos códigos locais, em um processo integrado. O objetivo do projeto, no primeiro momento, era realizar o diagnóstico da demanda expressa, para, posteriormente, desenvolver um planejamento de gestão participativa que aproveitasse e prestigiasse o saber local conforme as necessidades por eles vivenciadas. Neste relato, pretende-se apresentar alguns resultados dessa intervenção e discutir como se manifesta a identidade desses jovens através de atividades nas quais refletiram sobre sua escolha profissional.

\section{O caminho teórico}

Apresenta-se a perspectiva teórica que orienta e operacionaliza o presente estudo e a prática profissional. Adota-se o enfoque da Psicologia social, que estuda o comportamento dos indivíduos no que ele é influenciado socialmente. Logo, desde o nascimento, o ser já existe socialmente, vive em determinadas condições históricas que deram origem à família e vive e sobrevive exercendo uma determinada atividade. Assim, a Psicologia social apreende a relação essencial entre o indivíduo e a sociedade, sempre entendida historicamente, a partir do momento em que os seus membros se organizam para garantir sua sobrevivência até a forma pela qual seus costumes e valores são assimilados e transmitidos.

Essa influência histórica e social se faz sentir, primordialmente, pela aquisição da linguagem. Segundo Lane (1985, p.9), "as palavras, através dos significados atribuídos por um grupo social, por uma cultura, determinam uma visão de mundo, um sistema de valores e, em conseqüência, ações, sentimentos e emoções decorrentes". Uma comunidade específica, como a comunidade da Ilha do Mel, também desenvolve uma visão de mundo e um sistema de valores, que é compartilhado através da linguagem comum. Portanto, o estudo buscou, através das narrativas dos jovens, captar os interesses e motivações, sentimentos e emoções envolvidos na escolha profissional, bem como a importância e o sentido do trabalho para a manutenção dos jovens na Ilha do Mel. O significado do trabalho e os limites da escolha profissional são de fundamental importância na vida dos jovens dessa ilha.

O estudo da narrativa dos jovens ilhéus tem, como suporte teórico, as idéias de Vigotsky, principalmente ao tratar da indissociabilidade entre a constituição do pensamento e a verbalização deste pelos indivíduos. Ao pesquisar o significado de uma palavra, o autor nos orienta que este representa um amálgama tão estreito do pensamento e da linguagem que é difícil dizer se se trata de um fenômeno da fala ou de um fenômeno do pensamento. Uma palavra sem significado é um som vazio; o significado, portanto, é um critério da palavra, seu componente indispensável. O significado de cada palavra é uma generalização ou um conceito. Como as generalizações e os conceitos são inegavelmente atos do pensamento, podese considerar o significado como um fenômeno do pensamento. Daí não decorre, entretanto, que o significado pertença formalmente a duas esferas diferentes da vida psíquica.

O significado das palavras é um fenômeno de pensamento apenas na medida em que o pensamento ganha corpo por meio da fala, e só é um fenômeno da fala na medida em que esta é ligada ao pensamento, sendo iluminada por ele; é um fenômeno do pensamento verbal, ou da fala significativa - uma união da palavra e do pensamento (Vigotsky, 1987/ 2000).

Assim, através do estudo dos significados das palavras produzidos nas narrativas, é possível conhecer como o homem se insere no seu processo histórico, não apenas como ele é determinado, mas principalmente como ele se torna agente da sua história, como pode transformar a sociedade na qual vive. A ação do sujeito, o que este vai fazer em sua perspectiva de escolha profissional, depende do grau de autonomia e iniciativa alcançado por ele nas diversas relações sociais estabelecidas na comunidade, na família, com os colegas, na escola, nos diversos grupos dos quais participa.
"O significado das palavras é um fenômeno de pensamento apenas na medida em que o pensamento ganha corpo por meio da fala, e só é um fenômeno da fala na medida em que esta é ligada ao pensamento, sendo iluminada por ele; é um fenômeno do pensamento verbal, ou da fala significativa - uma união da palavra e do pensamento"

Vigotsky 
Os jovens da llha do $\mathrm{Mel}$ se encontramem determinadas circunstâncias sociais e estas interferem na possibilidade de escolha de uma atividade produtiva ou uma profissão.
Cabe questionar, sobre os jovens ilhéus, como esse contexto e suas relações sociais fornecem possibilidades de desenvolver projetos de vida e escolhas profissionais mais ou menos autônomas e se esses projetos permitem aos jovens permanecerem na ilha ou se contribuem para o êxodo dos mesmos.

No trabalho com comunidades, as técnicas de dinâmica de grupos são concebidas como instrumentos mediadores, capazes de desenvolver processos reflexivos e criativos sobre a realidade vivida nas comunidades. Ao participar das dinâmicas de grupo, o sujeito desencadeia processos reflexivos e criativos a partir de suas vivências grupais e, ao tomar suas práticas cotidianas de convivência como eixo central, o sujeito reflete sobre sua ação em um novo contexto; portanto, a relação grupal pode promover possibilidades de mudanças ao passar pela capacidade de criação de novos significados e sentidos que não estão dados.

As comunidades de ilhéus também sofrem os efeitos das transformações sociais e econômicas do sistema capitalista. Nos aspectos que dizem respeito a escolhas profissionais, essas transformações promovem novos tipos de trabalho. Diariamente se observa a extinção e a criação de novas profissões. Profundas modificações na vida das pessoas e nas oportunidades do mercado de trabalho estão ocorrendo e interferindo nas dinâmicas do trabalho em diferentes contextos ambientais.

Para os jovens ilhéus, o que este quer ser no futuro profissional e que tipo de trabalho pode vir a desenvolver são decisões que implicam condições objetivas de existência que trazem consigo limites e possibilidades para tecer escolhas profissionais adequadas e mais satisfatórias profissionalmente, mesmo frente às possibilidades e impossibilidades reais. Identificase a importância do trabalho do orientador profissional nesse sentido, principalmente sobre a possibilidade de sua atuação em contextos sociais excludentes.

Se, no meio urbano, já existem múltiplas limitações de escolha profissional, de possibilidades de trabalho, emprego e renda, o fato de habitar uma ilha pode impor ao sujeito novas e maiores dificuldades em tecer sua escolha profissional. Ser um pescador como os pais, ser um dono de pousada ou sair da ilha para ser um profissional diferente são possibilidades que fazem parte dos sonhos dos jovens, pois "as transformações associadas à modernidade libertaram o indivíduo de seus apoios estáveis nas tradições e nas estruturas" (Hall, 2005, p.25). O jovem se vê diante de uma multiplicidade de profissões e tem a necessidade de se conhecer e de definir uma escolha, com base na sua realidade pessoal e sociocultural.

Sobre o papel do orientador profissional, devese esclarecer que não há uma resposta pronta para a escolha, e sim, uma escolha consciente, a partir das escolhas adequadas naquele momento para aquele indivíduo, quando o jovem assume uma situação vivenciada e, compreendendo-a, pode chegar a uma decisão pessoal responsável (Bohoslavsky, 1993). Portanto, o processo de escolha é sempre do sujeito, e o objetivo da orientação profissional é "facilitar a escolha, participar, auxiliando a pensar, coordenando o processo para que as dificuldades de cada um possam ser formuladas e trabalhadas. (...) Coordenar não significa orientar, pois nós também não conhecemos o melhor caminho. Significa facilitar, para que o próprio jovem descubra quais caminhos pode seguir" (Soares-Lucchiari, 1993, p.12). A orientação profissional trabalha em três momentos distintos: o autoconhecimento, a informação profissional e, finalmente, a escolha propriamente dita.

Os jovens da llha do Mel se encontram em determinadas circunstâncias sociais e estas interferem na possibilidade de escolha de uma atividade produtiva ou uma profissão. Entre essas circunstâncias, estão a dificuldade do acesso à escola e problemas de formação educacional e profissional, além da impossibilidade de freqüência a cursos técnicos e de capacitação, fatos que revelam situações de exclusão social.

Ao invés de negar o conceito de exclusão como um conceito ambíguo ou monolítico que tem 
orientado as análises da desigualdade social, esse termo será mantido nesta pesquisa, pois, conforme Sawaia (2002, p.8), ele "aborda a exclusão social sob a perspectiva éticopsicossociológica para analisá-la como processo complexo, que não é em si, subjetivo nem objetivo, individual nem coletivo, racional nem emocional". É um conceito que orienta a reflexão para compreender suas dimensões e "a contrariedade que o constitui: a qualidade de conter em si sua negação e de não existir sem ela, isto é, ser idêntico à inclusão (inserção social perversa)". Defende a idéia de que todos estamos, de uma maneira ou outra, inseridos, alguns de uma forma perversa.

Portanto, os jovens ilhéus estão inseridos e se encontram em um determinado meio cultural que veicula os significados e sentidos do trabalho e da escolha profissional. Na abordagem de Vigotsky, a questão cultural e a construção de significados são constituídas como um processo mediado pela cultura. O conceito de cultura, proposto pelos estudos culturais, coloca um fim na dicotomia entre alta e baixa cultura. $\mathrm{O}$ rompimento das culturas de fronteiras traz diferentes preocupações e conseqüências e grandes oportunidades para o desenvolvimento de trabalhos com a interdisciplinaridade.

Nessa relação entre os estudos culturais e a abordagem histórica-cultural, buscou-se utilizar práticas grupais da orientação profissional, tendo em vista a compreensão e a análise das condições psicossociais envolvidas nas escolhas desses jovens em seus projetos profissionais. Este estudo desenvolveu-se no contexto da interdisciplinaridade, partilhando o conhecimento da Psicologia com a equipe técnica do projeto, formada, em sua maioria, por profissionais da biologia e da Educação. Constituiu-se uma intervenção na tentativa de compreender como os sujeitos se percebem e se posicionam frente a determinadas condições que influenciam suas possibilidades de escolha profissional.

\section{Contextualizado o grupo}

Os sujeitos convidados representam cerca de $10 \%$ da população na Ilha do Mel, ou seja, noventa e um jovens, compreendidos na faixa etária entre treze a vinte e cinco anos, que era o público-alvo do projeto, inseridos em um contexto no qual o trabalho de sobrevivência dos sujeitos está relacionado principalmente com o turismo ou com a pesca. Muitos ajustes também foram necessários quando se iniciou o projeto, pois o público-alvo se encontrava envolvido com atividades remuneradas, comuns nos meses de verão, quando o fluxo de visitantes na ilha aumenta de forma significativa. Essa situação fez com que a estratégia de adiamento do projeto fosse adotada, pois não seria possível envolvê-los em outras atividades nesse período.

Em conseqüência da concentração populacional em comunidades dispersas ao longo da ilha, as atividades do projeto foram planejadas para serem desenvolvidas com ênfase nas comunidades de Nova Brasília e Encantadas, localidades que concentram o maior número de jovens dentro desse público-alvo e que permitem melhores condições de acesso.

A condição objetiva de falta de perspectiva em relação às oportunidades de estudo e trabalho faz com que muitos desses jovens deixem suas comunidades em direção a centros urbanos como Paranaguá e Curitiba. Dessa forma, a necessidade de dar continuidade aos estudos obriga os jovens a realizá-los no continente, muitas vezes tendo como conseqüência a perda de sua identidade cultural, como habitantes da Ilha do Mel.

No continente, frente aos demais jovens, ser um "nativo" implica um processo de novas interações, nas quais o sujeito passa a constatar as diferenças e semelhanças em relação a um outro contexto. Inicialmente, percebe que não pertencer à cultura local pode pôr em risco sua adaptação, principalmente em função de outros conhecimentos escolares serem mais valorizados e decisivos para a sua aprovação. Tais condições limitam suas possibilidades de inserção dentro das características peculiares do saber na escola regular. Essas novas interações grupais que o jovem estabelece com as instituições do continente se constituem também em novas experiências identitárias. 
A identidade, na concepção sociológica clássica, é formada pela interação entre o eu e a sociedade. Para Hall (2005, p.11), o sujeito ainda tem um núcleo ou essência interior que é o "eu real", mas este é formado e modificado num diálogo contínuo com os mundos culturais "exteriores" e as identidades oferecidas por esses mundos. O contexto oferece aos jovens múltiplas possibilidades, entre ser nativo e não nativo, pertencer à ilha ou ao continente. $\mathrm{O}$ local de onde o sujeito vem, o que ele sabe ou faz para sobreviver pode influenciar sua identidade cultural e seu sentimento de pertencer a uma comunidade.

Compreende-se, no entanto, que "A identidade plenamente unificada, completa, segura e coerente é uma fantasia. Ao invés disso, à medida que os sistemas de significação e representação cultural se multiplicam, somos confrontados por uma multiplicidade desconcertante e cambiante de identidades possíveis, com cada uma das quais poderíamos nos identificar - ao menos temporariamente" (Hall, 2005, p.13). A contradição resultante das várias possibilidades de identificação decorrentes do lugar em que os sujeitos se inserem nas comunidades pode resultar em relações conflituosas que, reproduzidas nos pequenos grupos, implicariam resistência ao trabalho coletivo do projeto nas comunidades.

O principal objetivo da intervenção psicológica nesse contexto era possibilitar um papel ativo aos jovens, apreendido através de vivências grupais, a fim de que, em cada encontro, as atividades realizadas produzissem um efeito de maior participação e integração dos sujeitos, identificados com um projeto maior de âmbito comunitário e que beneficiasse a todos. O foco, num primeiro momento, era o de realizar um diagnóstico, para, posteriormente, desenvolver um planejamento de gestão participativa.

As atividades foram detalhadamente planejadas, porém "a realidade tem evidenciado a diversidade de expectativas e de necessidades de cada grupo. O planejamento é apenas o ponto de partida para o orientador; ele deve ser revisto a cada encontro, sendo adaptado às necessidades do grupo com o qual estamos trabalhando" (Soares, 2002, p.162). A despeito de todo planejamento, existem situações peculiares permeando o processo grupal, com características de expressão e comportamento distintas a serem consideradas, pois cada grupo se desenvolve em um processo próprio, em função das reais condições de vida e das peculiaridades dos participantes envolvidos.

Nas comunidades mais tradicionais da ilha, foi cedido, após negociações com as lideranças e autoridades instituídas localmente, o espaço das escolas para o trabalho com os grupos de jovens. Os encontros realizaram-se aos sábados e domingos, no período da manhã e da tarde, com cada uma das comunidades separadamente.

\section{Sobre a organização dos grupos de trabalho}

Sobre a perspectiva de mudança e transformação é que se formaram os grupos, em um processo que envolveu a negociação com as autoridades locais, a igreja, os líderes comunitários, as famílias e as demais instituições que organizam a vida comunitária no cotidiano da Ilha do Mel. Desenvolveu-se um diálogo com vistas a garantir a efetividade das ações em todos os aspectos que pudessem entrar em jogo na relação com os jovens e na sua participação no projeto. A metodologia qualitativa orientou a prática interdisciplinar e, conforme Guareschi (2003, p.81), "criativamente subverteu a ordem e as relações de forças instituídas nas ações de pesquisa e forneceu conhecimentos, através de forma de luta cultural e de poder, que permitiram uma nova perspectiva para a transformação e a mudança social".

Os estudos culturais descrevem metodologias plurais de trabalho, aproveitando campos discursivos para produzir o conhecimento exigido para um projeto particular de investigação, em que "o processo metodológico é o de alquimia, mesmo, resultando daí uma bricolagem diferenciada, estratégica e subvertedora das misturas homogêneas típicas da modernidade" (Guareschi, 2003, p.80). 
Na busca de integração deste estudo com as atividades do projeto, através de reuniões interdisciplinares, foram incorporadas contribuições de diversas áreas, como da biologia, da Educação e da Psicologia, a fim de buscar a elaboração e a sistematização de estratégias para a intervenção com as comunidades. Este estudo se insere no referencial proposto pelos estudos culturais, não apenas por se constituir num novo campo de estudos, mas por tentar construir um projeto político, capaz de empreender um esforço multidisciplinar conjunto como forma de intervenção.

Para a formação inicial dos grupos, foram elaborados cartazes explicativos sobre o projeto e foi feita a sua divulgação na rádio local, com chamadas para a participação dos jovens. Também foi adotada, como estratégia, a entrega de convites pessoais na casa de cada jovem residente, realizada através de várias visitas à llha do Mel e executada pela equipe técnica do projeto. Considerando os aspectos de dificuldade de acesso dos jovens, optou-se por realizar as reuniões iniciais nas escolas das duas comunidades locais mais populosas, Encantadas e Nova Brasília.

Como resultado das diversas chamadas para participar do projeto, não se tinha conhecimento da quantidade de sujeitos que compareceria efetivamente para as atividades, e pretendia-se organizar um esquema flexível para acomodar os presentes, que totalizaram vinte participantes em Nova Brasília e vinte e um em Encantadas.

Diante disso, em Nova Brasília, trabalhou-se com dois grupos, separados por sexo, e, apesar de não se considerar a questão do gênero para fundamentar a proposta do projeto, foi o mais adequado no momento, devido ao elevado número de participantes. Em Encantadas, trabalhou-se com os jovens presentes em uma só equipe. Foi de extrema relevância a possibilidade de distribuição diferenciada dos grupos, tendo em vista a necessidade de não manter qualquer distinção diferenciadora como idade, sexo, conhecimento ou experiência, acolhendo até mesmo o comparecimento de casais com os filhos pequenos. Segundo Soares (2002, p.163), "os encontros iniciais devem ser utilizados para buscarmos mais conhecimento de cada um por si próprio e para o orientador elaborar um diagnóstico inicial da situação específica de cada jovem". Portanto, essa compreensão possibilitou a flexibilidade necessária para a condução diferenciada dos grupos que se apresentaram para as atividades.

A responsabilidade ética é um fator inalienável, quando se tomam decisões que irão afetar profundamente outras pessoas. Para Moscovici (2002), um facilitador (coordenador), além de competência técnica, deve apresentar competência interpessoal, flexibilidade perceptiva, atitude experimental e capacidade de assumir riscos, fatores fundamentais na condução desses grupos.

No desempenho como psicóloga do projeto, buscou-se ocupar um lugar de coadjuvante das ações, resguardando o papel principal de vínculo com o grupo para os coordenadores do mesmo. Neste caso específico, a equipe era formada, em sua maioria, por biólogos. Nesse aspecto ético da atuação como coadjuvante, garantiu-se o relacionamento interpessoal mais próximo entre os coordenadores e os jovens. Segundo Moscovici (2002, p.26), "o relacionamento interpessoal pode tornar-se e manter-se harmonioso e prazeroso, permitindo o trabalho cooperativo, em equipe, com integração de esforços conjugando as energias, conhecimentos e experiências para um produto maior que a soma das partes". O trabalho interdisciplinar somou experiências, o que engrandeceu a atuação da equipe.

O objetivo comum estabelecido entre os técnicos do projeto, nesse primeiro momento, com os grupos, foi o de diagnosticar o que os jovens da llha do Mel precisam, querem ou gostariam de trabalhar no projeto Jovem, mostre a sua cara! A atuação psicológica se caracterizou pela observação das relações interpessoais dos sujeitos envolvidos e das intervenções nas atividades, a fim de manter um ambiente agradável e estimulante para a participação grupal. O desenvolvimento das atividades dos encontros, bem como a análise e a discussão dos resultados, serão descritos a seguir. 


\section{Desenvolvimento e discussão das atividades}

Recorreu-se à narrativa do jovem sobre sua vivência nos processos grupais, para analisar as repercussões subjetivas das condições psicossociais nas escolhas de seus projetos profissionais e trajetórias de vida e trabalho, bem como nos processos de constituição de sua subjetividade.

Constituição significa algo que faz parte, forma e compõe a subjetividade. O indivíduo acolhe as relações sociais ao configurar sua identidade pessoal, e também constrói uma história, um projeto de vida, que pode ser entendido como uma narrativa. Para Bruner (1998), a realidade psíquica domina a narrativa, e qualquer realidade existente além da consciência daqueles envolvidos na história é colocada pelo autor com o objetivo de criar efeito dramático. Assim, a narrativa trata das vicissitudes das intenções humanas.

A narração é um relato centrado num fato ou acontecimento; há personagens a atuar e um narrador que relata a ação. O tempo e o ambiente (ou cenário) são outros elementos importantes na estrutura da narração. Buscamos articular a noção de identidade cultural formulada por Hall (2005) com a narrativa produzida pelos grupos de jovens, com a idéia de ilustrar o movimento da identidade em sua dimensão concreta e abstrata considerada neste estudo.

Para revelar essas implicações, utilizamos a noção de projeto, entendido como aquilo que vai direcionar o ser constantemente para o futuro. O ser humano não absorve somente determinado papel social, pois, na dialética entre o indivíduo e a sociedade, a constituição da identidade implica o sentido de intencionalidade da ação humana. O ser desenvolve projetos de si mesmo, um vir a ser constantemente orientado para o futuro como possibilidade de ser. Segundo Soares (2002, p. 76), “o projeto é, ao mesmo tempo, o momento que integra, em seu interior, a subjetividade e a objetividade, é também o momento que funde, num mesmo todo, o futuro previsto e o passado recordado".
Os jovens da ilha tecem projetos e constroem para si o futuro desejado na esperança de que seus estudos e trabalho lhes permitam concretizar seus sonhos.

As narrações foram produzidas através do desenvolvimento de cinco atividades realizadas nas comunidades de Nova Brasília e Encantadas: 1) cartaz de diagnóstico coletivo, 2) dança das cadeiras, 3) jovem, mostre a sua cara, 4) atividade - gosto e faço (Soares-Lucchiari, 1993) e 5) a montanha.

Os resultados, distribuídos em categorias, retratam diferentes implicações que revelam as relações e contradições entre identidade cultural, projetos profissionais e trajetórias singulares de vida e trabalho. Essas categorias foram construídas a partir da análise do material produzido pelos jovens nas atividades acima, serão apresentadas em forma de texto e contêm as principais reflexões obtidas na análise dos processos grupais.

\section{Levantando necessidades e reconhecendo lideranças no grupo}

Na etapa inicial, a atividade cartaz de diagnóstico coletivo objetivou levantar o que os jovens precisam, querem e gostariam de trabalhar no projeto Jovem, mostre a sua cara! Com a utilização de tarjetas e canetas, cada um dos participantes produzia frases sobre o que o gosta e o que não gosta na ilha. Após a confecção individual das frases, as mesmas eram ordenadas e coladas em um cartaz coletivo. Nesse momento, todos os membros do grupo tinham condição de opinar sobre a seleção das frases, sua repetição e sobre os maiores problemas identificados. Em seguida, as frases foram lidas e coladas de acordo com o interesse do grupo, identificando os problemas mais urgentes para a coletividade.

No desenvolvimento, as melhores coisas da ilha foram classificadas como: a praia, a natureza, o verão, a comunidade, as festas típicas, a possibilidade de estarem em contato direto com 
a natureza, a liberdade para dançar, nadar e praticar esportes. Classificaram como as piores coisas da ilha as drogas, as brigas, os bêbados, a poluição, o lixo, os turistas mal-educados, o piche e a falta de escola.

Além das necessidades diagnosticadas, foi possível identificar o papel da liderança que se desenvolvia em cada um dos grupos. Segundo Moscovici (2002, p.26), "a liderança e a participação eficaz em grupo dependem essencialmente da competência interpessoal do líder e dos membros. O trabalho em equipe só terá expressão real e verdadeira se e quando os membros do grupo desenvolverem sua competência interpessoal". Alguns jovens assumiram o papel de líderes: Michele, Jhony, Izaque e Júnior. Essa participação dos líderes constituiu um processo de maior identificação dos indivíduos com os demais membros do grupo, ao refletirem sobre interesses que, a princípio, partiam de problemas individuais e que passaram, a partir dessas novas relações e narrativas, a serem comuns ao grupo. Essa experiência grupal de confecção coletiva do cartaz possibilitou novos significados sobre as necessidades grupais, tendo a liderança se alternado entre os jovens, na evidência de um esforço conjunto dos mesmos para expressar seus principais problemas.

A atividade permitiu a comunicação clara e espontânea dos jovens, tanto em Nova Brasília como em Encantadas, o que resultou num espaço para compartilhar a fala do jovem e possibilitou maior motivação e comunicação grupal, com a alternância de vários líderes na condução da atividade. O envolvimento grupal ocorreu de forma gradual, tímida no início da atividade, e foi se tornando cada vez mais produtiva e desinibida ao final da atividade. As identidades culturais foram evidenciadas, conforme orienta Hall (2005), naqueles aspectos que surgem do pertencimento a culturas étnicas, raciais, lingüísticas, religiosas e, acima de tudo, nacionais, sugerindo existir, dentro da comunidade, interesses, necessidades e anseios revelados no pertencimento a determinado grupo.
Como futura possibilidade de trabalho, surgiu a necessidade de maior articulação entre as comunidades, a fim de se fortalecer e reivindicar demandas sociais mais urgentes, como, por exemplo, a permanência de um médico no posto de saúde, funcionários no trapiche, a melhora na merenda escolar, mais barcas nos finais de semana e o acesso da cancha na escola situada na ilha. Essas reivindicações são necessidades para os jovens, já que os espaços de liberdade são determinados pelas "autoridades" locais. $\mathrm{O}$ enfrentamento dos obstáculos impostos aos indivíduos se dá pelo fortalecimento de um pensamento e da ação conjunta do grupo.

\section{Identificando-se ou reconhecendo-se como membro do grupo}

A segunda atividade, dança das cadeiras, objetivou melhor apresentação dos jovens de suas características peculiares e condições de vida, de forma a facilitar identificações e buscar a integração do grupo. Consistiu em distribuir os participantes em um círculo de cadeiras, com todos de frente uns para os outros, e com uma cadeira a menos do que o número total de participantes. A cada anúncio da coordenadora, os participantes deveriam trocar de cadeiras caso se identificassem com a consigna, alterada em perguntas como: quem tem mais de treze anos, quem trabalha, quem gosta de seu trabalho, quem tem namorado, quem gosta de novela, quem gosta de comer peixe, quem é o filho mais velho, etc. Aqueles que se identificassem deveriam trocar de cadeira. Sempre faltando um lugar para sentar, quem ficasse em pé deveria interagir com o grupo todo, explicando porque concordava ou discordava da consigna.

Observou-se maior integração grupal, o que permitiu conhecer cada um dos presentes através de suas narrativas, seus gostos e suas crenças, no enfoque dos aspectos afetivos, cognitivos e de comportamentos pelo relato de suas histórias e vivências diárias. Os jovens descobriram gostos comuns, identificaram-se através de preferências pela prática de esportes, descobriram em comum o time de futebol preferido, o fato de pertencerem a famílias 
"O fato de que projetamos a nós próprios, nessas identidades culturais, ao mesmo tempo em que internalizamos seus significados e valores, tornandoos "parte de nós", contribuipara alinhar nossos sentimentos subjetivos com os lugares objetivos que ocupamos no mundo social e cultural"

Hall numerosas, de gostarem de determinados programas de televisão, de possuírem os mesmos hobbies, o gosto pelos estudos, de serem filhos mais velhos ou mais novos. Frases que evidenciam como descrevem sua identidade de pertencimento: "sou do grupo de teatro", "sou da comunidade de Brasília", "adoro fazer capoeira", "adoro sair com a galera".

As identificações também foram obtidas pelas mesmas dificuldades enfrentadas em seu dia a dia, como a necessidade de deslocamento para dar continuidade aos estudos no continente, a falta comum e geral de recursos materiais para continuar seus estudos, a necessidade urgente de trabalho, a busca por um trabalho digno. A identidade, então, preenche o espaço entre o interior e o exterior, ou entre o mundo pessoal e o público.

Chama a atenção o fato de os jovens alinharem seus valores num determinado contexto cultural. "O fato de que projetamos a nós próprios, nessas identidades culturais, ao mesmo tempo em que internalizamos seus significados e valores, tornando-os "parte de nós", contribui para alinhar nossos sentimentos subjetivos com os lugares objetivos que ocupamos no mundo social e cultural" (Hall, 2005, p.12). É evidenciada, pelas narrativas dos jovens, a noção de pertencimento: "eu sou nativo... e nativo é quem nasce na ilha", "eu sou de fora...nasci em Paranaguá".

Nesse processo, observa-se a noção do eu relacionada ao local de nascimento como referência espacial e estável, que é um sistema de significados capaz de promover as igualdades ou diferenças entre os membros do grupo. Desse conhecimento de si mesmo, trabalhado lado a lado com os pares, surge a possibilidade de repensar suas relações com os outros e de se reconhecer como membro do grupo.

\section{Conhecendo a si mesmo ou autoconhecimento}

A terceira atividade, chamada de jovem, mostre a sua cara!, objetivou conhecer melhor quem eram e com quem se identificavam os membros do grupo. Foram distribuídas folhas, revistas, tesouras e canetas coloridas, de forma a facilitar a produção de um cartaz individual, no qual colavam um personagem com o qual se identificassem, ou seja, com a sua "cara". Após a confecção dos cartazes, os jovens deveriam apresentar descrições de si mesmos.

A partir do processamento dessa atividade, através dos desenhos e colagens resultantes, observam-se as auto-imagens adotadas pelos jovens, acompanhadas de relatos nos quais descrevem a si mesmos: gostam de participar de tudo, gostam do novo, são sonhadores, sinceros, simpáticos, alegres, amigos, originais, estudiosos, tranqüilos e felizes, assim como as narrativas que revelam seus valores e crenças: "eu não gosto de tatuagem", "eu detesto drogas", "eu sou muito estudiosa". Outras narrativas revelam seu temperamento "eu não levo desaforo para casa", "eu sou calmo... tranqüilo". Em outras, buscam uma descrição de seus sentimentos e emoções: "eu sou feliz." Muitos se mostram bastante inibidos ao apresentarem seus cartazes ou falaram sobre si mesmos; no entanto, ao conhecer o outro, passam a valorizar mais a si mesmos e a se reconhecerem no outro.

Essa atividade de autoconhecimento ajudou a perceber uma resistência das moças quanto ao fato de se aproximarem dos rapazes nativos; essas jovens preferem ir a bailes onde tenham a possibilidade de conhecer rapazes de fora da ilha. Percebe-se que a busca por conhecer jovens de fora tem relação com o "imaginário" ou fantasiado sobre essas identidades: "eu não gostei do baile... só tinha nativo", "eu gosto quando vem gente de fora". Os sujeitos assumem identidades diferentes, e, em diferentes momentos, identidades contraditórias. A presença de jovens "de fora" transforma as percepções de si mesmos; o fluxo intenso imigratório de jovens para a ilha traz, para o grupo de nativos, outros valores, costumes e comportamentos. Esses passam a assumir uma postura distinta e reproduzem, até mesmo na sua vestimenta, os hábitos dos "de fora". No entanto, quando ser nativo é valorizado pelo grupo, como na proteção da natureza e nos 
valores das tradições da ilha, essa identidade de nativo emerge: "eu sei tudo sobre as marés", "eu conheço as histórias da ilha" e é prontamente reforçada pelo grupo.

Contradições identitárias surgem quando os jovens são confrontados com situações onde seriam possíveis outras identificações; as representações do lugar ou culturais podem promover um conflito: "o próprio processo de identificação, através do qual projetamos nossas identidades culturais, tornou-se provisório, variável e problemático" (Hall, 2005, p.12). A responsabilidade pela preservação das tradições da ilha e pela própria posse do território local, de certa forma, reconduz os jovens a assumirem o papel de "nativos". Segundo a narrativa de um jovem: "Gosto de respeito e de ser respeitado pelas outras pessoas... Gostaria de compreender as pessoas para viver melhor". Esse trecho ilustra uma narrativa de si mesmo feita por um dos jovens participantes, que revela as emoções de angústia, nas quais o pensamento e a palavra procuram expressar sua história vivida e a sua relação com os demais.

\section{Conhecendo sentidos e significados das atividades para os jovens}

A quarta atividade, chamada de gosto e faço (Soares-Lucchiari, 1993), teve por objetivo facilitar o conhecimento de si mesmo em relação às escolhas profissionais e de trabalho. Foi solicitado que dividissem uma folha de papel em quatro partes e escrevessem, em cada parte, as atividades que gostam e fazem, gostam, mas não fazem, não gostam, mas fazem, e que não gostam e também não fazem. O interesse era identificar que preferências, valores e sentidos eram dados às suas atividades diárias no trabalho e conhecer um pouco mais as normas e costumes locais que definem o cotidiano dos jovens, com seus direitos e deveres. Entendese o homem a partir de sua história e da história da sociedade na qual está imerso, da compreensão dos elementos de sua cultura, de suas relações, contradições e confrontações estabelecidas ao longo de sua vida e nos espaços no qual elabora a sua interação com os outros.
Essa interação com os outros é mediada pela atividade, pois vivemos em uma sociedade em que a maioria dos indivíduos se organiza em torno do trabalho. Este é constitutivo do ser humano, configurado na sociedade moderna como o eixo mais importante de sua organização. "... O trabalho é um processo do qual participam o homem e a natureza, processo em que o ser humano, com sua própria ação, impulsiona, regula e controla seu intercâmbio material com a natureza (...) Atuando assim sobre a natureza externa e modificando-a, ao mesmo tempo modifica sua própria natureza" (Marx, 1987, p. 202). A instituição familiar define papéis e atribui responsabilidades de vida de direitos e deveres a cada um de seus membros, e essa estrutura familiar também determina atividades e trabalhos que servem para preservar a propriedade e os bens da família, sendo que os jovens devem ajudar a manter o grupo familiar.

Esse trabalho precoce instituído pela família é percebido, sentido e vivenciado em atividades das quais muitos jovens se envergonham de assumir, como cuidadoras de crianças, babás, carrinheiros (pessoas que levam as mochilas dos turistas visitantes), faxineira do trapiche. Evidencia-se, no grupo, uma distinção social de classe que separa aqueles que têm uma condição social um pouco melhor daqueles que precisam trabalhar para garantir sua sobrevivência, submetem-se a atividades que não gostam de desempenhar e que, no entanto, praticam por imposição da condição familiar. Nesse caso, o sentido possível do trabalho é o de necessidade: "eu tenho que trabalhar para ajudar minha família". Em outra narrativa, "eu faço faxina, sim... e daí?", consolida uma posição social do sujeito que impõe ao grupo a aceitação de sua atividade produtiva, da qual não se envergonha.

As identidades se mobilizam nos espaços de articulação de sentidos, de práticas, produzidas a partir da composição de determinadas narrativas, nas quais os sujeitos são posicionados e se reconhecem como sujeitos, não por aquilo com que se identificam, mas por aquilo que identificam como diferença, como nestes trechos de suas narrativas: "eu não faço carretos... nunca fiz", "eu já fiz... mas foi só 
uma vez, no verão". Ser carrinheiro, fazer carretos, apesar de serem atividades lucrativas, principalmente no verão, com o aumento do número de turistas na ilha, é, para alguns jovens, vergonha; para outros, motivo de orgulho.

Para outros jovens, o trabalho é visto como atividade penosa, ou enfadonha: "eu não gosto de trabalhar ensinando crianças", "eu não suporto o que faço". Os sentidos do trabalho se articulam e redefinem significados múltiplos no contexto grupal; representam orgulho, dependendo do status social do jovem: "eu trabalho com meu pai na loja". Já a mesma atividade, para outras jovens, traz um sentido de auto-realização: "eu adoro cuidar de crianças pequenas".

Da mesma forma que a identidade pessoal, a formação da identidade profissional deve ser entendida numa contínua interação entre fatores internos e externos ao indivíduo, pois, entre os que precisam trabalhar, existem aqueles que o fazem somente como parte das atividades domésticas, o que não é reconhecido como um trabalho: "Eu ajudo a mãe", "eu lavo louça, arrumo a casa", "eu trabalho com o pai na pousada", "eu trabalho na lojinha".

A afirmação da identidade implica sempre a demarcação e a negação do seu oposto, que é constituído como sua diferença. Esse 'Outro' permanece, contudo, indispensóvel.
Chama a atenção o fato de que alguns desses jovens, filhos de pescadores, não vêem a pesca como uma forma de trabalho capaz de garantir a subsistência. A pesca foi descaracterizada como um trabalho pelos jovens que, ao longo dos anos, acompanharam as alterações no ecossistema, como expresso em suas narrativas: "não adianta não... pescar não serve para viver", "tainha não dá mais", "nem a festa da tainha, não tem mais na ilha".

A afirmação da identidade implica sempre a demarcação e a negação do seu oposto, que é constituído como sua diferença. Esse 'outro' permanece, contudo, indispensável. A identidade negada é constitutiva do sujeito, fornece-lhe o limite e a coerência, e, ao mesmo tempo, assombra-o com a instabilidade. Não pode ser pescador, embora seja filho de pescador.

\section{Trajetórias de vida e escolhas profissionais}

A quinta atividade, chamada de a montanha, objetivou, através da confecção de um cartaz com o desenho de uma montanha e algumas mochilas, auxiliar o jovem a expressar seu desejo de fazer escolhas profissionais, onde gostaria de chegar e o que gostaria de ser na vida, o seu projeto profissional e a trajetória pretendida. $\mathrm{O}$ jovem foi solicitado a descrever cada passo da subida da montanha, dizer como faria para atingir seus objetivos concretos e o que deveria levar em sua mochila, para dar o próximo passo em direção a esses objetivos. Em resposta a essa atividade, as trajetórias de vida e escolha profissional apresentadas pelos jovens foram as seguintes:

Na comunidade de Nova Brasília, das meninas, oito gostariam de fazer algum curso superior, duas querem ser modelos; uma, jogadora de vôlei, e outra queria ter uma família. Aqui a escolha profissional reproduz o conhecimento de que a família também é um local de trabalho para a mulher. Dos meninos, dois gostariam de fazer curso superior; dois, de ser jogadores de futebol profissional; um, policial; um, guia turístico; dois, marinheiros, sendo um deles marinheiro "prático" (espécie de barco para conduzir grandes embarcações no porto). Esse jovem construiu claramente seu projeto profissional, traçando os passos para conseguir ser um marinheiro prático; detinha o conhecimento necessário para estabelecer uma trajetória profissional e havia pesquisado onde faria o curso e quanto custaria. Além dessa informação, também estava em estreito contato com os marinheiros do Porto de Paranaguá, e conhecia até mesmo qual a sua provável renda futura e o que poderia esperar com essa atividade profissional.

Na comunidade de Encantadas, das meninas, uma gostaria de fazer faculdade de contabilidade; uma, ser estilista; uma gostaria apenas de terminar os estudos (porque já era mãe); duas, atrizes; duas, veterinárias; duas, professoras de educação física; uma, modelo, e uma, costureira. Dos meninos, um gostaria de ser atleta; um, 
professor de educação física; um, biólogo; dois, jogadores de futebol; um, fazer uma faculdade (embora não tenha claro qual curso); dois, pescadores, e um, mergulhador profissional.

O ambiente social é o meio no qual a realidade objetiva vai sendo traduzida em realidade subjetiva, e a atividade, para o jovem, vai adquirindo um significado próprio, com um objetivo definido. Em sua maioria, a trajetória dos jovens é uma busca por independência, por autonomia e felicidade, como as narrativas ilustram: "depender dos pais é uma coisa chata", "eu quero ter a minha profissão para não depender de ninguém".

O trabalho é associado à independência financeira, ganha um sentido de projeto de vida, um projeto de independência, e é interiorizado também a partir da valorização dos estudos e do curso superior, como se o curso superior fosse uma garantia de sucesso profissional: "eu quero ser médica", "eu quero ser bióloga", "eu quero ser juíza".

Muitos jovens (dez) gostariam de ter um curso superior; outros estavam mais preocupados com o mercado de trabalho, sendo este um ponto importante na escolha profissional; no entanto, essa preocupação deve ser entendida de maneira relativa, principalmente em relação aos jovens no contexto da Ilha do Mel, pois estes não possuem muitos modelos de atividades profissionais que sirvam como orientação de projetos para o futuro.

Apesar de a grande maioria dos jovens desejar sair da ilha para continuar estudando, eles também afirmam que gostariam de voltar para trabalhar na ilha e ajudar sua comunidade a progredir e a preservar o meio ambiente, depois de formados. A escolha profissional faz parte de um projeto profissional que implica pensar o futuro, construir um cenário de realizações de interesses e desejos e que deve se estabelecer a partir do autoconhecimento.

Encontramos jovens com autoconsciência, o que aumenta a probabilidade de fazer uma escolha profissional mais realista. Os jovens do grupo que gostariam de ser mergulhadores, guias turísticos ou marinheiros justificam essas escolhas porque as percebem mais objetivamente ao alcance de sua capacidade de realização. Subjetivamente, sentem-se capacitados para serem bem sucedidos nessas atividades.

Percebem-se também diferentes graus de clareza ou de conhecimento sobre as dificuldades para atingirem seus objetivos, quando analisamos os cursos escolhidos. Alguns demonstraram maior grau de consciência para construir esse planejamento: "para ser juíza... primeiro tem que fazer um curso de Direito", “... depois tenho que prestar um concurso público...", "eu quero ser prático... para isso tenho que ser primeiro marinheiro... depois fazer o curso... daí eu consigo uma colocação no porto. É um ótimo emprego, dá para sustentar uma família. Eu já estou me preparando para isso".

Outros reconhecem a necessidade de cursos de capacitação e formação profissional e mobilizam-se para conseguir as informações necessárias, como acesso à biblioteca e buscas sobre informação profissional no computador do trapiche. Todos conhecem modelos de profissionais que visitam a ilha como turistas ou hospedam-se em suas casas de veraneio e pousadas, e conseguem estabelecer um projeto profissional mais adequado com suas condições e interesses. Outros jovens não dispõem de muita informação profissional, a não ser aquela veiculada pelos meios de comunicação, como a televisão, e outros ainda não sabem ao certo o que desejam ser no futuro ou como vencer as barreiras e limitações inerentes à Ilha do Mel.

\section{Considerações finais}

A partir desse relato da prática da orientação profissional em um diferente contexto, podemse analisar as várias condições psicossociais envolvidas na questão da escolha profissional. O projeto Jovem, mostre a sua cara! configurase como um estudo das possibilidades e limites da escolha profissional. Entre os limites da escolha, a questão da identidade, "quem posso vir a ser", ou qual o futuro profissional dos jovens ilhéus, é fortemente influenciada pela seu 
contexto. Os processos de identificação, especificamente os que envolvem grupos excluídos, como no caso específico dos jovens da Ilha do Mel, podem reduzir ou ampliar a efetiva participação em projetos de participação ou em atuações comunitárias.

A importância da identidade, para os ilhéus, é significativa porque repercute em sua participação ou não em programas que podem beneficiar as comunidades. A comunidade é o local de pertencimento, é onde os sujeitos sofrem todos os efeitos das transformações sociais e econômicas do sistema capitalista. A identidade cultural, na pós-modernidade, encontra-se em colapso, segundo Hall (2005), porque as mudanças estruturais estão alterando muito rapidamente as sociedades neste início de século. Como resultado, observa-se a fragmentação das paisagens culturais, de classe, de gênero, de sexualidade e de etnia, que, no passado, forneciam sólidas referências para os sujeitos.

A participação e articulação do psicólogo como coadjuvante, nessa atividade interdisciplinar, junto às comunidades de Nova Brasília e Encantadas, na Ilha do Mel, permitiu levantar, junto aos noventa e um jovens que participaram do projeto, as múltiplas necessidades locais, como a necessidade de espaços para o lazer e a necessidade de escolas, que permitam aos jovens dar continuidade a seus estudos. Também permitiu evidenciar a importância de reconhecer que as lideranças do grupo, para a articulação em projetos comunitários, são aquelas que definem espaços e possibilitam a participação dos jovens nativos ou não em um engajamento comunitário. Igualmente, as ações desenvolvidas com os grupos permitiram resgatar a importância de trabalhar a questão da identidade, em que processos de identificação permitem aos participantes se reconhecer como membros do grupo. As dinâmicas podem ser utilizadas como instrumentos mediadores, pois estimulam a reflexão e a criatividade grupal e possibilitam, aos jovens, ampliar seu autoconhecimento e reconhecer-se como membros de um grupo.

Quanto à questão da orientação profissional, é fundamental conhecer os sentidos e significados das atividades para os jovens, como a forma de sobrevivência e a possibilidade de sua permanência nas comunidades. As trajetórias de vida dos sujeitos são articuladas com suas escolhas profissionais e são tecidas em um contexto que possibilita um papel ativo dos jovens em suas descobertas. Pôde-se constatar que os subgrupos possuíam práticas de convívio diferenciadas, já que, entre os nativos e os de fora, observaram-se distâncias significativas de tratamento e certo preconceito. Através das identificações de pertencimento ao lugar de origem, os jovens, de certa forma, buscam construir uma narrativa do eu, que lhes fornece e desenvolve a segurança bem como assegura espaço territorial e político de ação e participação.

Por outro lado, com o desenvolvimento das atividades, percebeu-se, entre os "de dentro" da ilha e os "de fora", diferentes formas de superação que foram se construindo nos discursos dos membros do grupo. O desenvolvimento do trabalho, dentro do grupo, deu-se em um movimento, nem sempre consciente, de maior/ menor aceitação/rejeição ou maior/menor espaço e apoio ao outro, e procurou mobilizar interesses mais ou menos comuns em torno das problemáticas vivenciadas pelos jovens.

A escolha profissional se insere no projeto Jovem, mostre a sua cara! como uma condição para oportunizar espaço de diálogo, aceitar os questionamentos do jovem, buscar apropriar seus interesses frente à extrema complexidade do mundo contemporâneo, refletir sobre a realidade social em que esses jovens vivem e incentiválos na tarefa de realizar suas escolhas profissionais.Como a vida é única para cada um, o projeto profissional depende das crenças, valores, dons, vivências e sonhos individuais. Em todas as atividades, distinguem-se jovens que constroem projetos mais realistas, outros mais fantasiosos, e muitos que ainda não têm certeza de suas escolhas nem tampouco de suas possibilidades de escolha.

Quanto aos projetos profissionais, cumpre ressaltar ainda que não nascemos prédeterminados biologicamente a uma profissão; nossos recursos são múltiplos e a trajetória 
profissional é uma construção ao longo da vida, em que determinados interesses foram mais estimulados do que outros. As escolhas se situam em função de modelos profissionais oferecidos e idealizados, bem como de elogios e da valorização de algumas carreiras, em detrimento de outras, por parte de um determinado grupo social. Portanto, as vivências e experiências, em determinadas áreas profissionais, podem reforçar ou despertar novos interesses profissionais nos jovens.

Quanto ao planejamento de uma trajetória profissional futura, a grande maioria dos jovens ainda não têm definidas as etapas que precisam trilhar para atingir seus objetivos pessoais de vida e da carreira profissional. Observa-se que o simples fato de participarem dos grupos e refletirem sobre as expectativas futuras provocou um aumento de interesse do jovem em pensar sua trajetória profissional, seus caminhos e possibilidades de ação. As atividades desenvolvidas permitiram não só o próprio reconhecimento de suas capacidades e habilidades como o reconhecimento dos demais membros dos grupos, e resultaram também na sua identificação com o grupo e na sua mobilização para participar de ações comunitárias.

Para cumprir a sua finalidade, a orientação profissional deve ser operacionalizada da maneira mais coerente possível com as circunstâncias sociohistóricas encontradas e de acordo com o contexto no qual está inserida. Deve trabalhar com todas as técnicas disponíveis, promover o autoconhecimento do sujeito como um meio não só de facilitar a escolha profissional, mas de ajudar o indivíduo na elaboração de um projeto de vida mais pleno, que considere a multiplicidade de aspectos envolvidos na escolha do seu futuro pessoal e profissional.

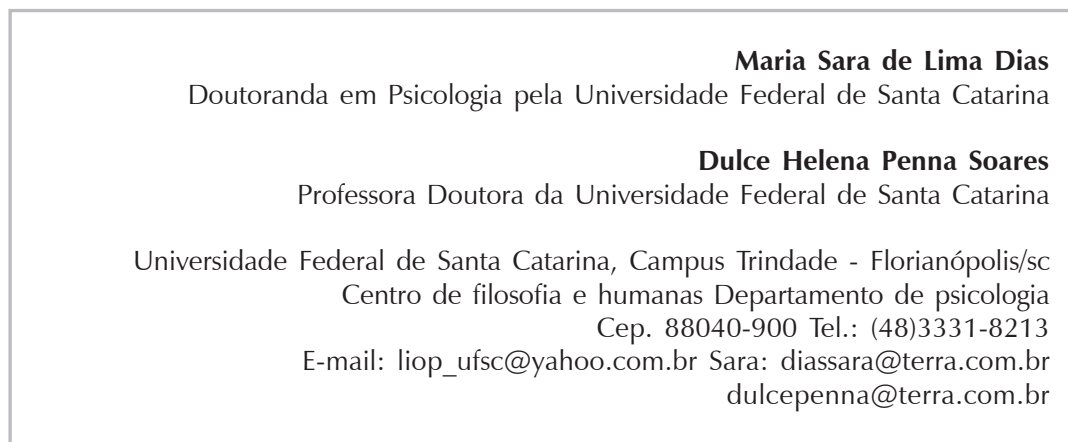

Recebido 10/06/05 Reformulado 14/11/06 Aprovado 18/12/06

BOHOSLAVSKY, R. Orientação Vocacional: a Estratégia Clínica. 9aㅡ ed. São Paulo: Martins Fontes, 1993.

BRUNER, J. Realidade Mental - Mundos Possíveis. Porto Alegre: Artes Médicas, 1998.

COSTA, A.F. Identidades Culturais Urbanas em Época de Globalização. Rev. Bras. Ci. Soc., vol.17, no 48, fev. 2002, pp.15-30.

GUARESCHI, N.M.F. Psicologia Social nos Estudos Culturais Petrópolis: Vozes, 2003.

HALL, S. A Identidade Cultural na Pós-modernidade. Rio de Janeiro: DP\&A, 2005.

LANE, S.M.T. O que É Psicologia Social. São Paulo: Brasiliense, 1985. MOSCOVICI, F. Desenvolvimento Interpessoal. Rio de Janeiro: LTC, 2002.
PRADO, R. M. As Espécies Exóticas Somos nós: Reflexão a Propósito do Ecoturismo na Ilha Grande. Horiz. Antropol., vol.9, no 20, out. 2003, pp.205-224.

SANTOS, M. S. História e Memória: o Caso do Ferrugem. Rev. Bras. Hist., vol.23, no 46, 2003, pp.271-295.

SOARES, D.H.P. A Escolha Profissional do Jovem ao Adulto. São Paulo: Summus Editorial, 2002

SOARES-LUCCHIARI, D. H. P. Pensando e Vivendo a Orientação Profissional. São Paulo: Summus, 1993.

VIGOTSKI, L.S. Pensamento e Linguagem. São Paulo: Martins Fontes, 1987-2000.
Referências 